\title{
Criação do curso de Pedagogia na Universidade Federal de Mato Grosso do Sul (1980-1996)
}

\section{Creation of the Pedagogy course at the Federal University of Mato Grosso do Sul (1980-1996)}

Resumo: $\mathrm{O}$ artigo tem por objetivo analisar o curso de Pedagogia na Universidade de Mato Grosso do Sul, campus Campo Grande, especificamente sua criação e consolidação no período de 1980 a 1996. Os procedimentos metodológicos utilizados compreendem a investigação bibliográfica e documental - leis, decretos, resoluções e pareceres —, também fontes institucionais - resoluções, pareceres, estatutos, atas de reunião e relatório anual - dos anos de 1970, 1980 e 1990. A proposta de iniciar o curso de Pedagogia com habilitação para atuar na pré-escola e nos primeiros anos do Ensino Fundamental foi inédito no Estado de Mato Grosso do Sul, poucas instituições no Brasil formavam os docentes para essa área. A criação do curso teve como principal objetivo atender à demanda da rede estadual de ensino que precisava de profissionais capacitados em nível superior.

Palavras-chave: História da Educação. Formação Inicial de Professores. Curso de Pedagogia.

Abstract: The article aims to analyze the Pedagogy course at the University of Mato Grosso do Sul, Campo Grande campus, specifically the creation and consolidation of the course between 1980 and 1996. The methodological procedures used include bibliographic and documentary research (laws, decrees, resolutions and opinions), also institutional sources (resolutions, opinions, statutes, minutes of meetings and annual report) from the 1970s, 1980s and 1990s. The proposal to start the Pedagogy course with qualification to work in pre-school and in the first years of elementary education it was unprecedented in the state of Mato Grosso do Sul, few institutions in Brazil trained teachers for this area. The creation of the course had as main objective to meet the demand of the state education network that needed trained professionals in higher education.

Keywords: History of Education. Initial Teacher Training. Pedagogy Course.

\section{Introdução}

Este artigo apresenta os resultados parciais de uma pesquisa de doutorado em andamento, cujo objeto é a história da criação do curso de Pedagogia da Universidade Federal de Mato Grosso do Sul, campus Campo Grande, e integra o grupo de pesquisa "Sociedade História e Educação" (GEPSE/HISTEDBR-MS), da Universidade Estadual de Mato Grosso do Sul, vinculado à Linha de Pesquisa "História, Políticas e Educação", do Programa 


\section{Edurañãa,Escola\&Sociedace}

de Pós-Graduação em Educação da Universidade Federal de Mato Grosso do Sul (UFMS).

O objetivo do artigo é o de analisar o curso de Pedagogia do campus Campo Grande da UFMS, especificamente, a sua criação e consolidação institucional no período de 1980 a 1996. O referido recorte temporal foi definido em decorrência da divisão do Estado de Mato Grosso em 1977, que originou a criação do Estado de Mato Grosso do Sul, acontecimento que antecede a criação do curso de Pedagogia no ano de 1980 e encerra o período de análise com a aprovação da Lei de Diretrizes e Bases da Educação (LDB), Lei n 9394/96, que instala novo marco regulatório na organização da educação brasileira ${ }^{1}$. Ainda, foram consideradas as reformulações nas políticas de formação inicial de professores ocorridas na área da Pedagogia em nível nacional, durante a ditadura militar, e a posterior democratização do país, bem como as mudanças implementadas na educação superior pública brasileira nesse momento histórico.

Os procedimentos metodológicos utilizados compreendem a investigação bibliográfica e documental, sendo consultadas e sistematizadas fontes institucionais dos anos de 1970 e 1980, tais como: leis, decretos, resoluções, pareceres, estatutos, atas de reunião do colegiado do curso de Pedagogia e relatório do Centro de Ciências Humanas Sociais da Universidade Federal de Mato Grosso do Sul (UFMS).

Ressalta-se que o curso de Pedagogia, do campus Campo Grande da UFMS, foi implantado precisamente quando o Brasil vivenciava esse momento histórico, o regime da Ditadura Civil Militar. Com efeito, na segunda metade da década de 1970, em decorrência da conjuntura política, econômica e social que passava o país, o regime começou a ser questionado no âmbito das universidades e escolas, e o campo educacional iniciou sua organização, impulsionado em grande medida pela oposição à pedagogia oficial e à política oficial dominante (SAVIANI, 1997). Com base nessa conjuntura, será analisado, a seguir, o processo histórico no qual se instituiu o mencionado curso.

\section{Caracterização histórica do Brasil: implicações na política educacional de formação inicial de professores (1970-1990)}

No Brasil, o período que antecedeu à década de 1970, especificamente o ano de 1964, marcou o país com profundas mudanças políticas e ideológicas. Com efeito, em março desse

\footnotetext{
${ }^{1}$ Kullok (2000, p. 11) apresenta que a LDB propõe diversos loci de formação, "como as últimas determinações das autoridades governamentais a respeito das funções dos cursos de Pedagogia, e sua possibilidade ou não de formar professores".
} 


\section{Edtuañangisolar Sociedace}

ano, ocorreu um golpe civil militar, o presidente João Goulart (1961-1964) foi deposto e iniciou-se a ditadura, mediante o Ato Institucional n ${ }^{\circ} 1$, de 9 de abril. Foram suspensos os direitos políticos dos opositores ao regime, bem como cassação de mandatos e prisão dos mesmos (VIEIRA, 2015).

Os primeiros anos de governo militar foram marcados por corte de gastos no setor público, aumento de tarifas e impostos, restrição de crédito, arrocho salarial, recessão e desemprego. A relação com o capital estrangeiro ficou cada vez mais estreitada mediante a venda de empresas nacionais - ocasionada pela desvalorização da moeda do país - e os novos empréstimos, provocando uma aproximação cada vez maior com os Estados Unidos (VIEIRA, 2015).

Os anos de 1970 expressaram o auge da ditadura, com prisões, torturas e assassinatos dos opositores e intensa repressão e eliminação de qualquer movimento ou indivíduo que fosse vinculado ao comunismo (MENEZES e SANTOS, 2001). Entre os anos 1969 e 1973, período chamado de milagre econômico, houve crescimento do PIB em 11,1\%, bem como facilidade de crédito para a aquisição de bens de consumo duráveis. O crescimento da economia contrastou com o aumento da dependência do capital e petróleo estrangeiro e com o aprofundamento das desigualdades sociais no país, porque se deu um processo de concentração de renda, além de corrupção e má utilização dos recursos públicos (FAUSTO, 1996; BIANCHI MENDEZ, 2004).

Acrescenta-se nesse contexto a preocupação do governo militar pela grande "legião de iletrados", cuja nomenclatura foi utilizada pelo presidente Emílio Garrastazu Médici (1969-1974) para se referir aos analfabetos — e a educação passou a ser um importante instrumento de controle ideológico e ascensão social. As implicações desses fatores desencadearam duas medidas: a estipulação de normas para o vestibular em 1971, pelo Decreto n ${ }^{\circ} 68.908$ e a Reforma do Ensino de $1^{\circ}$ e $2^{\circ}$ Graus, Lei 5.692/1971.

Inaugurou, nesse período, uma nova estrutura para o curso de formação de professores mediante a Lei no 5.692/1971, definida com caráter de habilitação. Segundo Saviani (2009), o

[...] parecer n. 349/72 (Brasil-MEC-CFE, 1972), aprovado em 6 de abril de 1972, a habilitação específica do magistério foi organizada em duas modalidades básicas: uma com a duração de três anos (2.200 horas), que habilitaria a lecionar até a $4^{a}$ série; e outra com a duração de quatro anos (2.900 horas), habilitando ao magistério até a $6^{\mathrm{a}}$ série do $1^{\mathrm{o}}$ grau. $\mathrm{O}$ currículo mínimo compreendia o núcleo comum, obrigatório em todo o território nacional para todo o ensino de $1^{\circ}$ e $2^{\circ}$ graus, destinado a garantir 


\section{Edurañagescolar Sociedtare}

a formação geral; e uma parte diversificada, visando à formação especial. $\mathrm{O}$ antigo curso normal cedeu lugar a uma habilitação de $2^{\circ}$ Grau. A formação de professores para o antigo ensino primário foi, pois, reduzida a uma habilitação dispersa em meio a tantas outras, configurando um quadro de precariedade bastante preocupante. (p. 147)

Verifica-se, no fundamento da reforma, que a profissionalização compulsória preconizada por meio da implantação das Habilitações Específicas para o Magistério (HEM) foi tratada como uma questão de formação de recursos humanos para a educação dentro da ótica tecnicista que imperava no programa oficial do governo. Nesse momento histórico, a educação era direcionada para o treinamento profissional. O crescimento do número de matrículas, aperfeiçoamento da qualidade de ensino e estímulo aos cursos de pós-graduação foram aspectos educacionais que interessaram ao governo do general Ernesto Beckmann Geisel (1974-1979), como destaca Vieira (2015).

Destaca-se que o presidente Geisel assumiu a presidência e o Movimento Democrático Brasileiro (MDB) conquistou um expressivo número de legisladores nas eleições legislativas. Sinais de uma crise econômica se manifestavam progressivamente, devido ao aumento do preço do petróleo e da dívida externa. Geisel mostrou-se mais moderado e tentou promover uma abertura com a oposição. A sociedade civil passou a reivindicar os direitos democráticos e com o fim das imposições do AI-5 progrediu a abertura política, mesmo que lentamente. (VIEIRA, 2015)

O general João Baptista de Oliveira Figueiredo (1979-1985) assumiu o poder. Junto a isso, centenas de exilados voltaram ao país e foi restabelecida a estrutura pluripartidária. A crise econômica agravou-se provocando manifestações e aumento de greves (VIEIRA, 2015). Como destaca Fausto (1994), o governo estabeleceu relações paradoxais ao mesmo tempo que lentamente deu abertura à formação de novas siglas partidárias, buscando manter o controle político e econômico. A missão que assumiu em levar o país às vias de um regime democrático, colidia com o agravamento econômico.

Os fatos históricos, políticos e sociais ocasionaram desdobramentos que redefiniram o papel do Estado e impactaram a forma de produção da sociedade capitalista. O fim do regime militar (1964 - 1985) teve início com a lei da anistia em 1979, que possibilitou a volta de centenas de exilados ao país. Aconteceu também o fim do bipartidarismo, isto é, regime de dois partidos, o Movimento Democrático Brasileiro (MDB) e a Aliança Renovadora Nacional (ARENA) que provocou a mudança do nome do partido da base aliada do governo, que passou a se chamar Partido Democrático Social (PDS) e a do partido da oposição, denominado Partido do Movimento Democrático Brasileiro (PMDB). Outrossim, se 
intensificou a organização de novos partidos, dentre eles, o Partido dos Trabalhadores (PT), o Partido Democrático Trabalhista (PDT) e Partido Trabalhista Brasileiro (PTB). O regime enfraquecido foi objeto de mobilizações e organização de passeatas, comícios que exigiam a retomada das eleições diretas e da democracia (ROMANELLI, 1999).

Dentre essas transformações, destaca-se o movimento dos trabalhadores que lutavam pela qualidade da educação pública e, no quadro geral, pela democratização da sociedade. Essas lutas políticas e pedagógicas dos docentes trouxeram relevantes contribuições para a educação, em especial, para a formação de professores (FREITAS, 2002).

Ressalta-se ainda que, de maneira concomitante, o embate neoconservador alcançou sua maior expressão nos finais dos anos 1980, e sustentava uma forte crítica sob as formas do Estado Benfeitor ${ }^{2}$ e o Estado Keynesiano ${ }^{3}$ que alertavam a respeito das "terríveis" consequências políticas, econômicas e sociais das propostas de políticas públicas que pretendem corrigir os problemas das diferenças sociais dos setores de menores recursos (HARVEY, 2008; MONTAÑO, 2008).

A década de 1980 também foi marcada pelo discurso democrático como eleições diretas para governadores e prefeitos. Com isso, em 10 de fevereiro de 1980, foi criado o Partido dos Trabalhadores com o registro na Justiça Eleitoral. Em 1984, o Brasil foi movido por uma campanha por eleições diretas para presidente da república, chamada de Diretas Já; uma emenda constitucional foi apresentada para que a eleição ocorresse de forma direta, porém, recebeu o veto do Congresso Nacional (ALMEIDA, 2011; VIEIRA, 2015).

Em 1985, por eleição indireta, venceu o oposicionista Tancredo de Almeida Neves — pela coligação Aliança Democrática entre os partidos MDB e Partido da Frente Liberal (PFL). Tancredo morreu e assumiu a presidência José Sarney de Araújo Costa (1985-1990). Durante seu governo, foi elaborada uma nova Constituição, para substituir a carta adotada pelo regime militar em 1967 (SILVEIRA, 2009).

A Assembleia Constituinte foi formada em fevereiro de 1987, e a Constituição da República Federativa do Brasil aprovada em 1988, que incorporou uma série de demandas sociais, entre elas as relacionadas com a democratização da educação e saúde públicas. Além

\footnotetext{
${ }^{2}$ O Estado de Bem-Estar é fortemente questionado a partir da década de 1960, com o surgimento das doutrinas de caráter monetarista, neoliberal e conservadora, manifestando que este Estado de caráter assistencialista não soluciona os conflitos sociais senão que os aprofunda porque impede que as forças do mercado funcionem livremente (MONTAÑO, 2008).

3 Teoria política econômica proposta por John Maynard Keynes que defendia no contexto da sociedade capitalista de mercado a intervenção do estado para promover o desenvolvimento econômico, mediante a manutenção do pleno emprego e o controle da inflação (MONTAÑO, 2008).
} 


\section{EdurañäsEscolakSociedade}

disso, foram estabelecidas as eleições diretas, independência dos poderes legislativo, executivo e judiciário, restrição à atuação das forças armadas e garantia o direito à greve, entre outras medidas (VIEIRA, 2015).

Porém, o processo de descrédito e crítica ao Estado, iniciado em décadas anteriores, aprofundou-se nos anos 1990 em todos os países da América Latina, adotando diferentes características conforme as conjunturas nacionais. No Brasil, foram implementadas as políticas neoliberais a partir do governo de Fernando Collor de Melo/Itamar Franco (19901994). Collor, depois de ser deposto pelo processo de impeachment, assumiu a presidência Itamar Franco (1992-1995), que designou Fernando Henrique Cardoso (FHC) para o Ministério da Fazenda e das Relações Exteriores. Nessas pastas ministeriais, como ministro, chefiou a elaboração do Plano Real, que estabilizou a economia.

Segundo Fiori (1995), "FHC foi concebido para viabilizar no Brasil a coalizão de poder capaz de dar sustentação e permanência ao programa de estabilização do FMI, e viabilidade política que faltava ser feito das reformas preconizadas pelo Banco Mundial”. (p. 14). Com a ajuda do sucesso do plano, foi eleito Presidente da República no primeiro turno da eleição de 1994.

O governo de FHC (1994-1998) inaugurou uma nova ofensiva neoliberal no país ao encaminhar o Projeto de Emenda Constitucional n ${ }^{\circ} 173$ sobre a reforma do aparelho do Estado brasileiro. Com o suporte da popularidade conquistada pela estabilização da economia, o novo presidente principiou sua administração estruturando uma ampla reforma nas políticas e nos aparelhos de Estado, para reduzir o custo Brasil, solucionar a crise da economia brasileira e garantir as condições de inserção do país na economia globalizada. Prosseguiu com as reformas econômicas iniciadas; as taxas de inflação continuaram baixas; houve a privatização de diversas empresas e a abertura de mercado, que deu maior visibilidade no mercado externo (ANTUNES, 2005).

No campo educacional, no ano de 1996, depois de o projeto tramitar por 13 anos no Congresso Nacional, foi sancionada a nova Lei de Diretrizes e Bases da Educação Nacional, Lei $N^{\circ}$ 9.394/1996, cujos princípios ideológicos democráticos e participativos expressavam em todas as normativas o reordenamento da educação no país. Estabeleceu novos lócus de formação docente, além das instituições universitárias, previa a criação de Institutos Superiores de Educação, que suscitaram intensos debates (SAVIANI, 1997).

Entre os anos de 1970 a 1990, no campo educacional, ocorreram fatos determinantes para o engajamento dos trabalhadores em educação na luta por políticas educacionais 
democráticas, de qualidade, sobretudo, referentes à formação de professores. Contudo, a viabilidade desses movimentos dos educadores teve o apoio de entidades que subsidiaram as discussões e debates que ocasionaram as conquistas que se efetivaram posteriormente na promulgação da LDBN 9.394/1996 (SAVIANI, 1997).

Em sequência, apresenta-se uma breve aproximação à história do curso de Pedagogia, e organização dos trabalhadores em educação em parceria com as associações constituídas entre os anos de 1970 a 1990, na luta pelas reformulações das políticas públicas de formação docente.

\section{O curso de pedagogia no Brasil: aspectos históricos e marcos legais}

O curso de Pedagogia no Brasil, no decorrer de sua história, enfrentou inúmeras modificações curriculares, as quais interferiram na sua estrutura, bem como a identidade dos profissionais da educação. Esse curso foi criado mediante o Decreto-lei no 91.190, de 04/04/1939 e teve início na Faculdade de Filosofia da Universidade do Brasil, apresentando na sua estrutura quatro eixos fundamentais: Filosofia, Ciências, Letras e Pedagogia, bem como uma seção direcionada ao curso de Didática (BRASIL, 1939).

Destaca-se que o Instituto Superior de Educação, que funcionava anexo à Faculdade de Filosofia, Ciências e Letras, inaugurado em 1901 pela Ordem das Beneditinas de São Paulo, tinha o intuito de formar os professores em nível superior. Entretanto, não conseguiram ser efetivados continuando a formação desses educadores apenas nas escolas normais em nível secundário (SAVIANI, 2008).

No Decreto-lei no 9 1.190/1939, o Artigo 19 estabelece a duração de três anos para o curso e as disciplinas que deveriam ser cursadas na primeira, segunda e terceira séries da formação do pedagogo. Apresenta na Secção XI, a estrutura curricular para o curso de Pedagogia (BRASIL, 1939).

As disciplinas foram organizadas da seguinte forma: na primeira série, as disciplinas complementares de Matemática, História da Filosofia, Sociologia, Fundamentos Biológicos da Educação e Psicologia Educacional. Na segunda série, Estatística Educacional, História da Educação, Fundamentos Sociológicos da Educação, Psicologia Educacional e Administração Escolar. Na terceira série, História da Educação, Psicologia Educacional, Administração Escolar, Filosofia da Educação e Educação Comparada (BRASIL, 1939).

O curso, durante os três anos, formava o bacharel em Pedagogia, que recebia a 


\section{EdurañäsEscolakSociedade}

denominação de "Técnico de Educação". Segundo Coelho (1987, p. 9), "não fica claro, então, o que seria esse técnico de educação, qual sua função e especificidade em relação aos profissionais formados nas várias licenciaturas e nos outros bacharelados. A definição desse técnico de educação permanece bastante fluida".

Assim, a licenciatura em Pedagogia era obtida com mais um ano de estudos no curso de Didática que habilitava os professores ao exercício do Magistério nos Cursos Normais. Por meio do Decreto-lei no 3.454/1941, o curso de Didática deveria ser cursado depois da formação no bacharelado, sendo proibido matrículas simultâneas num curso de bacharelado e no curso de Didática (BRASIL, 1941).

O Decreto-lei n ${ }^{\circ}$ 9.092, do ano de 1946, objetivou alterar a organização do curso de Pedagogia, definindo que a formação seria de quatro anos para as duas habilitações: bacharelado e licenciatura. Entretanto, não ocorreu essa modificação visto que a maior parte das faculdades não efetivou essa determinação legal e manteve a organização conhecida como 3+1 (BRASIL, 1946).

Silva (1999) apresenta a estrutura curricular do curso de Pedagogia das instituições de ensino superior brasileiras que organizou as disciplinas do bacharelado da seguinte maneira: Complementos de Matemática (1 $1^{\mathrm{a}}$ série); História da Filosofia (1ª série); Sociologia (1 ${ }^{\mathrm{a}}$ série); Fundamentos Biológicos da Educação (1 ${ }^{\mathrm{a}}$ série); Psicologia Educacional (1 $1^{\mathrm{a}}, 2^{\mathrm{a}}$ e $3^{\mathrm{a}}$ séries); Estatística Educacional ( $2^{\mathrm{a}}$ série); História da Educação ( $2^{\mathrm{a}}$ e $3^{\mathrm{a}}$ séries); Fundamentos Sociológicos da Educação (2 ${ }^{\mathrm{a}}$ série); Administração Escolar (2 $2^{\mathrm{a}}$ e $3^{\mathrm{a}}$ séries); Educação Comparada ( $3^{a}$ série); e Filosofia da Educação ( $3^{a}$ série). Para a habilitação em licenciatura acrescentavam-se as disciplinas de Didática Geral, Didática Especial, Psicologia Educacional, Administração Escolar e Fundamentos Sociológicos da Educação.

Dessa forma, ao término do curso de Pedagogia, bacharelado, para garantir as duas habilitações o profissional deveria cursar as disciplinas de Didática Geral e as Especiais que não são apontadas na grade curricular (SILVA, 1999).

Como destacado por Silva (1999), o curso apresentava dificuldades relacionadas às questões teóricas, que eram pouco discutidas nas disciplinas oferecidas e apresentava características técnicas; outro fator preponderante era a inexistência de pesquisas na matriz curricular. Nesse sentido, a formação dos educadores estava fundamentada nas atividades práticas, tornando o curso alvo de críticas e intimidações de extinção.

Nesse contexto, foram inseridas no campo educacional normas legais como a Lei de Diretrizes e Bases da Educação Nacional, Lei n. 4.024/1961, que modificou a estrutura 
curricular mediante o Parecer $n^{\circ}$ 251/1962 e posteriormente teve novas alterações com a promulgação do Parecer no 252/1969 (BRASIL, 1961; 1962; 1969).

No ano de 1962, o Conselho Nacional de Educação (CNE), por meio do Parecer n ${ }^{\circ}$ 251/1962, em decorrência da Lei 4.024/1961, fixou um currículo mínimo constituído por sete matérias sendo cinco obrigatórias — eram Psicologia da Educação, Sociologia (Geral da Educação), História da Educação, Filosofia da Educação e Administração Escolar — e duas opcionais - Biologia; História da Filosofia; Estatística; Métodos e Técnicas da Pesquisa Pedagógica; Cultura Brasileira; Educação Comparada; Higiene Escolar; Currículos e Programas; Técnicas Audiovisuais de Educação; Teoria e Prática da Escola Média; e Introdução à Orientação Educacional. Esse Parecer também estipulou a duração de quatro anos para o curso de Pedagogia, e incluiu o bacharelado e a licenciatura. Segundo Saviani (2008, p. 42),

quanto à duração do curso, foi definida em quatro anos, englobando o bacharelado e a licenciatura, correspondendo, portanto, à duração anterior. A diferença fica por conta de certa flexibilidade, uma vez que as disciplinas de licenciatura poderiam ser cursadas concomitantemente com o bacharelado, não sendo necessário esperar o quarto ano.

Recorda-se que a rigidez da situação anterior era tal que o Decreto-Lei n 3.454, de julho de 1941, "proibiu a todas as faculdades de Filosofia, Ciências e Letras a realização simultânea do curso de Didática com qualquer dos cursos de bacharelado" (MENDONÇA, 2002 , p. 153). Com a nova regulamentação deixava de vigorar o esquema conhecido como “3+1".

Outro aspecto que foi destacado por Romanelli (1978) é que nesse momento histórico prevaleceram os interesses da iniciativa privada. Assim, a duração do curso ficou definida em quatro anos, unindo o bacharelado e a licenciatura. Permitiu a existência de duas matrículas para cursar ao mesmo tempo as disciplinas referentes às habilitações de licenciatura e bacharelado.

Uma segunda reformulação do curso foi realizada a partir do Parecer $n^{\circ}$ 252/1969 e a Resolução no 02/1969 do Conselho Nacional de Educação, que manteve a estrutura padronizada do formato $3+1$, coincidindo com as demais licenciaturas. Como afirma Coelho (1987, p. 10), neste ano "se procurou, pois, tornar mais explícito e mais preciso o que em 1962 ainda estava latente, implícito, difuso e impreciso.”

A mudança na organização do Estado brasileiro como consequência das demandas 


\section{Edurañãa,Escola\&Sociedace}

da produção capitalista, alterou as políticas de formação de professores desenvolvidas nas últimas décadas, suscitando desdobramentos de natureza política, econômica e social. Este fenômeno desencadeou investigações e discussões entre os pesquisadores da educação com o objetivo de compreender a indução de tendências e orientações nas políticas educacionais (MONTAÑO, 2008).

No período final da década de 1970, a formação de professores era tratada como uma questão de formação de recursos humanos para a educação dentro da ótica tecnicista que imperava no pensamento oficial. Em 1980, as referidas concepções foram combatidas pelo movimento dos trabalhadores que lutavam pela qualidade da educação pública e no quadro geral pela democratização da sociedade. Essas lutas políticas e pedagógicas dos docentes trouxeram relevantes contribuições para a educação, em especial, para a formação de professores ${ }^{4}$ (FREITAS, 2002).

Nesse período, havia no país um grupo de estudiosos que buscava romper com o pensamento tecnicista que predominava na área da educação. Os movimentos, por meio das associações Sociedade Brasileira para o Progresso da Ciência (SBPC), Centro de Estudos Educação e Sociedade (CEDES), Associação Nacional pela Formação dos Profissionais da Educação (ANFOPE) e Associação Nacional de Pós-Graduação em Educação (ANPED), realizavam debates que discutiam as concepções sobre a formação dos profissionais de educação, evidenciando as características sócio-históricas dessa formação, a necessidade de um profissional formado com um conhecimento sobre a ampla realidade do seu tempo, com postura crítica e propositiva para que consiga transformar as condições da escola, da educação e da sociedade (MACIEL e NETO, 2004).

Apesar das inúmeras discussões e questionamentos sobre a formação de professores, a década de 1980 chega ao seu final sem que se tenha elaborado uma proposta concreta sobre o fazer pedagógico por parte das universidades e seus cursos de Pedagogia. Dentre os grandes fatos ocorridos nesse período, pode-se destacar a criação do Comitê Pró-Formação do Educador (1980), constituído por dois grupos de intelectuais, um que incorpora a produção do poder instituído, o outro a produção do coletivo de educadores (KULLOK, 2000).

\footnotetext{
${ }^{4}$ Segundo Freitas (2002, p. 138) os movimentos dos educadores contribuíram com "a forma de olhar a escola e o trabalho pedagógico, ao colocar em evidência as relações de determinação existentes entre educação e sociedade e a estreita vinculação entre a forma de organização da sociedade, os objetivos da educação e a forma como a escola se organiza".
} 
O primeiro grupo ${ }^{5}$ é homogêneo, inclui a produção de documentos que conservam uma forma monolítica, sem mudanças, o sistema preconizado pelo Conselho Nacional de Educação, propondo alguns princípios transformadores. O segundo grupo ${ }^{6}$, heterogêneo, revela muitas tendências de transformação assumidas e divulgadas pela própria práxis. Procuravam unir a compreensão teórica à compreensão do real, relacionar a atividade teórica à prática (KULLOK, 2000).

Como se pode observar, havia uma imperiosa necessidade de modificar os cursos de formação de educadores e a urgência de estabelecer articulações entre a universidade com os demais níveis de ensino, e com as diversas entidades de classes e grupos representativos da comunidade. Proclamava-se a premência de uma maior autonomia universitária e participação da comunidade acadêmica nas decisões universitárias gerando condições para a revalorização do profissional da educação.

Assim, o movimento com sua concepção emancipadora da educação e da formação avançou no sentido de superar as dicotomias presentes na formação dos profissionais de educação, ou seja, na formação acadêmica entre professores e especialistas, bacharelados e licenciaturas, especialistas e generalistas, acompanhando a escola na busca da democratização das relações de poder em seu interior e na construção de novos projetos coletivos (MACIEL e NETO, 2004).

Durante os anos 1990, principalmente no período do governo Fernando Henrique Cardoso (FHC), entre 1995 e 2002, surgiram várias ações regulatórias, normas legais, direcionadas à formação dos professores. Segundo Moon (2008, p. 802), “[...] a impressão geral é de que mais atenção política foi dada à educação dos professores na década de 1990 do que nas centenas de anos de história que a precederam, e que a maior parte dessas ações enfocou a qualidade".

\footnotetext{
${ }^{5}$ A proposta básica que deu sustentação à produção do poder instituído foi o "pacote pedagógico" de Valnir Chagas, que não se tratava de mudanças de estruturas, estava constituído pela faculdade de educação e seus conteúdos específicos. Transferência de estudos pedagógicos para os institutos, o que permitiria a formação do professor e do especialista nos mencionados institutos. Esvaziaram-se, assim, as funções da Faculdade de Educação. Sugeria que as unidades acadêmicas que se ocupavam da educação deviam organizar-se em centro de ensino e pesquisa. Também, formava parte destas análises o documento "Conclusões gerais da Comissão Ensino da Área de Educação - CEAE/MEC” divulgado por Roberto Moreira em 9/12/1980, afirmava que a faculdade de educação e as "unidades de conteúdo" deveriam criar os centros interdepartamentais (KULLOK, 2000).

${ }^{6} \mathrm{Na}$ linha de trabalho heterogêneo destaca-se o trabalho de Saviani, em 1982 para quem o lugar adequado para formar educadores é o centro de educação, porém esse centro não envolve apenas os cursos de pedagogia, mas os cursos de formação de educadores. Assim, a concepção de escola única de formação de professores materializa-se no centro de educação. Mantém um núcleo básico comum de formação, que requer uma estrutura universitária que viabilize a integração e a totalidade dos estudos pedagógicos num espaço traduzido como escola única de formação de nível superior (KULLOK, 2000).
} 


\section{Edurañãa,Escola\&Sociedace}

Sendo assim, a criação dos Institutos Superiores de Educação (IES), a oferta de cursos de formação como os cursos normais superiores, cursos de graduação em Pedagogia e outras licenciaturas expandiram-se principalmente em instituições privadas. O crescimento dos IES pela iniciativa privada foi um dos pilares que sustentaram a política neoliberal que busca a efetivação de um mercado educacional livre e consequentemente fazer da educação mais uma mercadoria do sistema capitalista (MACIEL e NETO, 2004).

Nesse período, a Associação Nacional pela Formação dos Profissionais da Educação (ANFOPE) teve papel fundamental no redirecionamento das discussões travadas no âmbito oficial sobre formação de professores. Tal instituição, de caráter político-acadêmico, originária do movimento dos educadores na década de 1970, teve um papel importante no cenário nacional quando se trata de desenvolver estudos, pesquisas e debates sobre a formação e valorização dos profissionais da educação (ANFOPE, 1998).

A ANFOPE participou da aprovação das diretrizes curriculares do curso de Pedagogia que consideraram diversas proposições elaboradas no âmbito dos movimentos dos educadores. Atuou ativamente na formulação das diretrizes para o curso de Pedagogia com uma proposta de que "o princípio da docência como base da formação profissional de todos aqueles que se dedicam ao estudo do trabalho pedagógico” (ANFOPE, 1998, p. 10).

Essas diretrizes, materializadas mediante a Resolução $\mathrm{CNE} / \mathrm{CP} \mathrm{n}^{\circ}$ 1, de 15 de maio de 2006, que institui as Diretrizes Curriculares Nacionais para o Curso de Graduação em Pedagogia, licenciatura, foram o resultado de um amplo debate que contribuiu para firmar progressivamente a concepção de identificar a Pedagogia com a função docente, na perspectiva de que o ensino deve ser a base da formação de todo educador (SILVA, 1999).

No contexto dos anos 1990 ocorreu a promulgação da Lei de Diretrizes e Bases da Educação Nacional, Lei n. 9.394/1996, resultado de dois projetos: o primeiro elaborado pelas entidades da sociedade civil e o segundo, articulado pelo senador Darcy Ribeiro que causou polêmica no Congresso Nacional, pois desencadeou muitas contradições e grandes avanços (GATTI, 2011). Tal lei admite que o professor dos primeiros anos do Ensino Fundamental tenha formação em nível médio.

As instituições de ensino superior assumiram a responsabilidade pela formação inicial e continuada dos professores da educação básica conforme o artigo 63, incisos I, II e III, da Lei 9.394/1996 (BRASIL, 1996), para realizar e manter os cursos formadores de profissionais para a educação básica.

Assim, seguindo o Parecer CNE/CP no 04/1997, proposta de resolução referente ao 
programa especial de formação de Professores para o $1^{\circ}$ e $2^{\circ}$ graus de ensino e outros documentos foram elaborados com o intuito de orientar a formação dos professores como: os Referenciais Curriculares para Formação de Professores (1999), o Parecer no 115/1999 que dispõe sobre os Institutos Superiores de Educação de acordo com os Artigo 62 e 63 da Lei 9.394/1996 e o Artigo 9", \ 2, alíneas "c" e "h" da Lei 4.024/1961, com a redação dada pela Lei 9.131/1995, bem como as Diretrizes Curriculares para a Formação Inicial de Professores para a Educação Básica em Nível Superior (2001). Tais documentos direcionaram a organização curricular dos cursos de formação profissional.

Nesse momento histórico, a formação dos professores recebeu uma relevância estratégica para a efetivação das reformas educativas que culminaram na homologação das Diretrizes Curriculares Nacionais para a Formação de Professores da Educação Básica em Nível Superior, por meio da Resolução CNE/CP nº 1, de 18 de fevereiro de 2002 (SCAFF, 2011).

A seguir, discute-se o histórico do curso de Pedagogia na Universidade Federal de Mato Grosso do Sul tendo como base a análise da política educacional de formação inicial de professores em âmbito estadual a partir da década de 1980, depois da divisão do Estado de Mato Grosso, e das reformas nas políticas de formação inicial de professores ocorridas na área da Pedagogia no contexto nacional e as implicações para a região sul-mato-grossense.

\section{O curso de Pedagogia na Universidade Federal de Mato Grosso do Sul}

A história do curso de Pedagogia da Universidade Federal de Mato Grosso do Sul ${ }^{7}$, campus Campo Grande, iniciou sua trajetória na década de 1980 com a criação do Centro de Ciências Humanas e Sociais, em 11 de março de 1980 que, posteriormente, acolheria o curso de Pedagogia (MAYMONE, 1989).

\footnotetext{
7 A instituição teve sua origem em 1962, com a criação da Faculdade de Farmácia e Odontologia de Campo Grande, na cidade de Campo Grande, inserindo o ensino superior público no sul do então Estado de Mato Grosso. A Lei Estadual no 2.620, de 26 de julho de 1966, possibilitou a criação do Instituto de Ciências Biológicas de Campo Grande que instituiu departamentos e o curso de Medicina, bem como reformulou a estrutura anterior. Em 1967, o governo do Estado de Mato Grosso amplia a rede pública de ensino superior com a criação em Corumbá do Instituto Superior de Pedagogia e, em Três Lagoas, do Instituto de Ciências Humanas e Letras. Posteriormente, a integração dos Institutos de Campo Grande, Corumbá e Três Lagoas ocorreu a promulgação da Lei Estadual no 2.947, de 16 de setembro de 1969, que criou a Universidade Estadual de Mato Grosso (UEMT). Na década de 1970, foram criados os Centros Pedagógicos de Aquidauana e Dourados, incorporados à UEMT. Com a divisão do Estado de Mato Grosso, foi concretizada a federalização da instituição que passou a denominar-se Fundação Universidade Federal de Mato Grosso do Sul, pela Lei Federal $\mathrm{n}^{\circ}$ 6.674, de 5 de julho de 1979. O Centro Pedagógico de Rondonópolis passou a integrar a Universidade Federal de Mato Grosso (UFMT) (MAYMONE, 1989).
} 


\section{EdurañäsEscolakSociedade}

A Secretaria de Estado da Educação de Mato Grosso do Sul, juntamente com a Universidade Federal de Mato Grosso do Sul, foram protagonistas na criação do curso como consta no Oficio no $6071 / 1030 / \mathrm{SE} / 1980$, emitido pela referida Secretaria e enviado para o reitor da universidade, solicitando o estudo de criação de cursos de nível superior que contemplasse a área pedagógica para atender os profissionais em exercício da Rede Estadual de Ensino de Campo Grande que atuavam nos níveis de $1^{\circ}$ e $2^{\circ}$ graus (UFMS, 2013).

Alguns critérios foram estabelecidos pela Secretaria de Educação para que a universidade atendesse à formação inicial dos profissionais de educação da rede em potencial com um curso no período noturno para que os alunos continuassem desenvolvendo suas atividades nos períodos matutino e vespertino. O quantitativo de 644 docentes em exercício precisava da formação (FERNANDEZ, 1989).

Ressalta-se que o documento apresentado por Fernandez (1989) destacou a importância da universidade pública na formação da força de trabalho qualificada, na abertura de maiores perspectivas de auto-realização e no melhor desempenho do profissional da educação.

A solicitação realizada pela Secretaria de Educação foi atendida e iniciaram-se as discussões sobre a criação e aprovação do curso de Pedagogia com habilitação em Magistério das Séries Iniciais de $1^{\circ}$ Grau e Magistério da Pré-Escola a ser instalado para o campus universitário de Campo Grande. Para tanto, uma comissão foi instituída e designada pela diretoria do Centro de Ciências Humanas e Sociais (CCHS) (UFMS, 2003).

Em relação às habilitações escolhidas no momento da criação do curso de Pedagogia foram primeiramente em decorrência das prioridades levantadas pela Secretaria de Educação e pela justificativa presente no plano do curso, que objetivou auxiliar o sistema estadual de educação, bem como pela disponibilidade de recursos humanos altamente qualificados e espaço físico disponível na universidade no período noturno (FERNANDEZ, 1989).

A implantação das estruturas curriculares das habilitações em Magistério nas Séries Iniciais do $1^{\circ}$ Grau e no Magistério da Pré-Escola, bem como da habilitação em Supervisão Escolar foi procedida de ampla discussão entre os docentes, a Pró-Reitoria de Assuntos Acadêmicos, Coordenadoria Geral de Planejamento da UFMS e também consultados profissionais de outras instituições que ministravam o curso de Pedagogia. Assim, mediante a Portaria 129-A de 1980, da Reitoria, em 15 de novembro foi aprovada a estrutura curricular (UFMS, 1980).

A comissão responsável pela implantação do curso na instituição buscou 
informações junto às universidades que ofereciam essas novas habilitações tais como a Universidade Metodista de Piracicaba, localizada no Estado de São Paulo, e a Universidade Federal de Santa Maria, no Estado do Rio Grande do Sul (FERNANDEZ, 1989).

Dessa forma, o curso de Pedagogia na Universidade Federal de Mato Grosso do Sul entrou em funcionamento no $1^{\circ}$ semestre de 1981 com a habilitação em Magistério nas Séries Iniciais do $1^{\circ}$ Grau, dando-se o ingresso mediante vestibular com a abertura de 30 vagas. Posteriormente, no segundo semestre do mesmo ano, iniciou-se a turma com habilitação no Magistério da Pré-Escola (FERNANDEZ, 1989).

Diferentemente dos outros $\operatorname{cursos}^{8}$ presentes nos demais campi da UFMS, o curso de Pedagogia na cidade de Campo Grande iniciou com as habilitações de licenciatura para o Magistério da Pré-Escola e Magistério para as Séries Iniciais do $1^{\circ}$ Grau e a carga horária do curso era superior à dos outros campus totalizando 3056 horas (UFMS, 2003).

A primeira coordenadora do curso foi a professora mestre Jane Mary Abuhassan Gonçalves, indicada em 6 de abril de 1981 mediante a Portaria nº 077/1981 da Reitoria, que regulamentava as atividades de responsabilidade do professor responsável pela coordenação do curso (UFMS, 1981).

O curso de Pedagogia, com as habilitações apontadas, funcionou até 1982, dentro dos moldes previstos. A partir daí, ocorreu uma unificação nas estruturas curriculares dos cursos de licenciatura regulamentada pelas Resoluções 60/1982 e 72/1982 do Conselho de Ensino Pesquisa e Extensão (UFMS, 1982).

Ainda em 1982, depois da aprovação dessas resoluções, a estrutura curricular do curso de Pedagogia foi modificada com o objetivo de atender as ponderações dos docentes e discentes para adequar a formação a uma nova realidade presente na região sul-matogrossense. Em paralelo, a comissão designada pela diretoria do Centro de Ciências Humanas e Sociais iniciou um estudo do perfil do profissional do curso de Pedagogia (GONÇALVES, 1989).

O curso de Pedagogia obteve sua autorização de funcionamento em 3 de agosto de 1983 por meio do Parecer no 375/1983 do Conselho Nacional de Educação. O Plano do Curso de Pedagogia foi aprovado sem a habilitação de Supervisão Escolar que também era prevista para ser ofertada, entretanto não foi ativada (UFMS, 2013).

\footnotetext{
${ }^{8}$ O curso de Pedagogia nos demais campi da Universidade Federal de Mato Grosso do Sul foi implantado na cidade de Ponta Porã e Três Lagoas, em 1970, e Corumbá, em 1973.
} 


\section{Edurañãa,Escola\&Sociedace}

Em setembro de 1983, a Comissão responsável pelos estudos para a definição do perfil do profissional da educação apresentou o seu trabalho e propôs a realização do I Seminário Interno do Curso de Pedagogia, que discutiu o documento elaborado pela comissão de estudos para a definição do perfil do profissional de educação (GONÇALVES, 1989).

Assim, o I Seminário Interno do Curso de Pedagogia aconteceu no período de 5 a 9 de dezembro de 1983 e teve como objetivo discutir e analisar o perfil do profissional da educação. Os participantes foram professores, alunos, autoridades educacionais, entidades envolvidas no processo educacional, estudiosos da pré-escola e ensino básico (GONÇALVES, 1989).

Nesse contexto, ainda no ano de 1983, identificou-se em uma das reuniões nacionais de coordenadores do curso em relação a estrutura curricular do curso de Pedagogia que não existia disciplina destinada à alfabetização (GONÇALVES, 1989).

Dessa forma, no $1^{\circ}$ semestre do ano de 1984 , entrou em vigor a nova estrutura curricular aprovada pelo Conselho de Ensino e Pesquisa (COEPE) por meio da Resolução 57/1983 que incluía a habilitação magistério das matérias pedagógicas de $2^{\circ}$ Grau (UFMS, 2013).

Ressalta-se que ocorreu um erro na publicação do edital do concurso de vestibular, de certo modo foi desfavorável ao curso de Pedagogia, pois prejudicou a organização das estruturas do curso invertendo a ordem da proposta inicial que era no primeiro semestre com a habilitação para séries iniciais e o segundo semestre oferecer a habilitação para a pré-escola. Porém, na publicação do edital ficou ao contrário e, para evitar que outros problemas viessem a ocorrer, permaneceram as definições previstas em edital propondo a utilização do curso de verão quando futuramente aparecessem as defasagens (GONÇALVES, 1989).

O curso de Pedagogia enfrentou outros problemas no ano de 1984, com a necessidade de contratação de professores para as disciplinas Prática de Ensino nas Séries Iniciais I e II, e Estágio Supervisionado que foram sendo discutidos e resolvidos.

Quando a primeira turma do curso estava prestes a concluir sua formação, a coordenação do curso iniciou um Projeto de Acompanhamento do aluno egresso do Curso de Pedagogia no intuito de verificar as oportunidades de emprego e aceitação no mercado de trabalho (FERNANDEZ, 1989).

Em seguida, a Secretaria de Educação do Estado de Mato Grosso do Sul abriu 
concurso Estatual de Professores da $1^{\mathrm{a}}$ a $4^{\mathrm{a}}$ série e os formandos tiveram a oportunidade de concorrer às vagas de professores.

Em 29 de maio de 1984, a UFMS recebeu uma Comissão Verificadora formada pelas professoras Clélia de Feitas Capanema, da Universidade de Brasília, e a professora Roseli Cecília Rocha de Carvalho Baunsel, da Universidade Federal do Pará, para o reconhecimento do curso de Pedagogia cuja avaliação foi positiva e as docentes constataram condições favoráveis de funcionamento (GONÇALVES, 1989).

Assim, o reconhecimento do curso de Pedagogia, com as habilitações em Magistério das Séries Iniciais do $1^{\circ}$ Grau, da Pré-Escola e Matérias Pedagógicas foi aprovado pelo Parecer 691/1984 em 05 de outubro de 1984 e publicado no dia 14 de novembro de 1984 no Diário Oficial da União (UFMS, 2013).

Em 1985, cria-se o colegiado do Curso de Pedagogia de acordo com o Estatuto da UFMS formado pela então coordenadora do curso, professora Eurize Caldas Pessanha, e os professores José Luiz Magalhães, Alzira Mongelli, Therezinha de Alencar Selem e a representante discente Mirian Morello.

Nesse momento, o curso enfrentou dificuldades para a contratação de professores para as matérias específicas da pré-escola e por causa da exigência no edital de convocação não tiveram inscritos no concurso. Assim, houve alteração no edital diminuindo o nível de exigências para realização do concurso.

Novos impasses surgem, os egressos do curso que foram aprovados no concurso para docente do estado não estavam conseguindo assumir por causa da legislação estadual em vigência no período que não admitiam formação em nível superior. Entretanto, com a intervenção da Secretaria de Educação de Mato Grosso do Sul, Procuradoria Geral do Estado, e administração da Universidade Federal de Mato Grosso do Sul, os candidatos tiveram sua nomeação efetivada no Nível $\mathrm{V}$ da carreira do magistério correspondente à formação em Ensino Superior (FERNANDEZ,1989).

No primeiro semestre de 1985 iniciou-se a organização do III Seminário do Curso de Pedagogia, mas com a paralização ${ }^{9}$ dos professores das universidades brasileiras o evento

\footnotetext{
${ }^{9}$ As Universidades Federais no ano de 1985 realizaram uma paralização de 45 dias no período de 10 de agosto a 23 de setembro. As reinvindicações dos profissionais foram reposição salarial de 38,5\%, implantação de reajuste trimestral, adicional de $5 \%$ a cada quinquênio, adicional por dedicação exclusiva de no mínimo 50\%, adicional de 5\% de produtividade, aposentadoria integral e reajuste para custeio das instituições de ensino superior. A greve das Universidades Brasileiras resultou em algumas ações do Ministério da Educação como a elaboração de um novo Plano de Cargos e Salários para as Instituições de Ensino Superior. (SINDICATO DOS DOCENTES DA UNIVERSIDADE FEDERAL DE SANTA MARIA, 2019)
} 


\section{EdurañäsEscolakSociedade}

ocorreu somente no período de 2 a 6 de dezembro de 1985. O tema de discussão foi "A prática do ensino em questão" (FERNANDEZ, 1989).

Entretanto, para atender ao curso, a universidade contratou temporariamente os professores solicitados e conseguiu finalizar o semestre no dia 10 de janeiro de 1986. Nesse ano, outros problemas foram evidenciados como a evasão de alunos que estavam insatisfeitos com o curso e afirmavam que faltavam informações no edital do vestibular como a exigência de experiência previa no Magistério de $2^{\circ}$ Grau que posteriormente entraria em discussão.

Nesse período, os acadêmicos do curso realizaram uma mobilização no $2^{\circ}$ semestre do ano de 1986 com o objetivo de reivindicar, por meio de uma lista de propostas, a retirada da exigência de experiência no Magistério de $2^{\circ}$ Grau.

No IV Seminário do Curso de Pedagogia, que ocorreu nos dias 20 a 24 de outubro de 1986, foi colocada em discussão a habilitação em Magistério de $2^{\circ}$ Grau e acordado que, diante das reinvindicações dos alunos, uma comissão de estudos seria formada com professores e alunos com o objetivo de elaborar alguns instrumentos avaliativos periódicos e constantes para o curso.

A professora Denise Tibau de Vasconcelos Dias assumiu a coordenação do curso no final do segundo semestre do ano de 1986. Outrossim, iniciou-se a discussão sobre a avaliação do curso de Pedagogia. Em 12 de novembro de 1986, na posse da nova coordenadora, a professora Eurize Caldas Pessanha, foi apresentado um balanço das atividades do curso mediante sua atuação na coordenação do curso, no colegiado e com a criação do centro acadêmico.

Durante o ano de 1987, o currículo e a avaliação do curso foram discutidos. Em 15 de novembro de 1987, realizou-se uma consulta à Pró-Reitora de Ensino referente à fusão das habilitações Séries Iniciais e Pré-escola, pois os egressos do curso, principalmente os formandos da Pré-escola, estavam com dificuldades para ingressar no mercado de trabalho representado pelo sistema estadual e municipal de ensino (GONÇALVES, 1989).

Em 1988, durante o V Seminário do curso de Pedagogia "Repensando o curso de Pedagogia", realizado no período de 3 a 7 de outubro, foi novamente discutida a estrutura curricular do curso, e destacado que no decorrer da elaboração do Plano do Curso de Pedagogia foram descritos os objetivos específicos de cada habilitação, a estrutura curricular, duração do curso e o corpo docente responsável pela sua implantação.

Mediante a Resolução UFMS, n. 145, de 26 de outubro de 1990, foi fixada a carga 


\section{Edtuañangisolar Sociedace}

horária do curso de Pedagogia que começou a ter 2.445 horas para as habilitações técnicas e de 2.415 horas para as habilitações referentes ao Magistério com duração de três anos (UFMS, 1990).

Em 1992, a carga horária do curso foi alterada por meio da Resolução UFMS nº 086, de 18 de dezembro, estabelecendo quatro anos de duração com 2.500 horas nas habilitações técnicas e 2.480 horas para as habilitações de magistério. Contudo, os cursos ficaram com 2.618 horas, com duração de quatro anos.

As Resoluções $n^{\circ}$ 121, aprovada no ano de 1995, dispõe sobre o currículo pleno, matriz curricular, ementário e tempo útil do curso definindo as seguintes disciplinas na organização curricular: Filosofia da Educação, com 204 horas; História da Educação, com 136 horas; História da Educação Brasileira, com 68 horas; Psicologia da Educação, com 204 horas; Sociologia Geral da Educação, com 136 horas; Sociologia da Educação, com 68 horas; Educação Física, com 68 horas; Iniciação à Pesquisa Educacional, com 102; Didática, com 136 horas; Didática para as Séries Iniciais, com 68 horas; Pesquisa Educacional, com 136 horas; e Trabalho de Conclusão de Curso, com 68 horas (UFMS, 1995).

Como pode depreender do exposto, o curso de Pedagogia teve momentos distintos em sua trajetória. Primeiramente, a preocupação legal e burocrática para consolidação e funcionamento na UFMS, campus Campo Grande, o segundo momento foi marcado pela busca de equilíbrio entre as habilitações ofertadas, sua articulação com o mercado de trabalho e a busca pelo seu crescimento.

\section{Considerações}

O curso de Pedagogia foi implantado no campus Campo Grande da Universidade Federal de Mato Grosso do Sul em um momento histórico, caraterizado pelo modelo tecnicista que privilegiava a formação de especialistas. Nesse contexto, criou-se o curso com o objetivo de atender à demanda da rede estadual de ensino que precisava de profissionais capacitados para atuarem nas séries iniciais do ensino fundamental e da pré-escola.

No período analisado de 1980 a 1990, verifica-se que o movimento dos profissionais de educação engajados nas associações, como a ANFOPE, e nos sindicatos reivindicaram para que se incluísse a formação de professores como uma política educacional sistemática, e contribuiu para consolidação do curso de Pedagogia em âmbitos nacional e estadual.

Dessa maneira, a universidade, perante a solicitação da Secretária de Educação, 


\section{EdurañäsEscolakSociedade}

compôs uma comissão para estudo e viabilidade do curso na capital do Estado. Para tanto, ficou decidido, por ambas as partes, que a formação seria no período noturno em função da disponibilidade dos docentes em exercício e do espaço físico da universidade estar disponível.

A proposta de iniciar o curso de Pedagogia com as habilitações direcionadas para a formação de professores com habilitação para atuar na Pré-escola e no Magistério das Séries Iniciais de $1^{\circ}$ Grau foi inédito no Estado de Mato Grosso do Sul, considerando que poucas instituições no Brasil formavam os docentes para essa área como a Universidade Metodista de Piracicaba, localizada no Estado de São Paulo, e a Universidade Federal de Santa Maria, no Estado do Rio Grande do Sul. Assim, prevalecia cursos de Pedagogia que formavam profissionais que atuavam fora da sala de aula nas áreas de orientação pedagógica, supervisão escolar e gestão escolar.

\section{Referências}

ALMEIDA, Gelsom Rozentino. História de uma década quase perdida — PT, CUT, crise e democracia no Brasil: 1979-1989. Rio de Janeiro: Garamond, 2011.

ANFOPE. Documento Final do IX Encontro Nacional da Associação Nacional pela Formação dos Profissionais da Educação. Campinas, 1998.

ANTUNES, Ricardo. A desertificação neoliberal no Brasil (Collor, FHC e Lula). 2. ed. Campinas: Autores Associados, 2005.

BIANCHI MENDEZ, Alvaro Gabriel. O ministério dos industriais: a Federação das Indústrias do Estado de São Paulo na crise das décadas de 1980 e 1990. 2004. 314f. Tese. (Doutorado em Ciências Sociais) - Instituto de Filosofia e Ciências Humanas. Universidade Estadual de Campinas. Campinas.

BRASIL. Conselho Nacional de Educação. Parecer no 375, de 3 de agosto de 1983. Autoriza o funcionamento do curso de Pedagogia. Brasília: Diário Oficial da União, 03 ago. 1983.

BRASIL. Decreto-lei no 3.454, de 24 de julho de 1941. Dispõe sobre a realização simultânea de cursos nas faculdades de Filosofia, Ciências e Letras. Rio de Janeiro: Diário Oficial da União, 26 jul. 1941.

BRASIL. Decreto-lei no 91.190 , de 04 de abril de 1939. Dá organização à Faculdade Nacional de Filosofia. Rio de Janeiro: Diário Oficial da União, 6 abr. 1939.

BRASIL. Decreto-lei no 9.092, de 26 de março de 1946. Amplia o regime didático das faculdades de Filosofia, e dá outras providências. Rio de Janeiro: Diário Oficial da União, 28 mar. 1946.

BRASIL. Lei no 4.024, de 20 de dezembro de 1961. Fixa as Diretrizes e Bases da Educação Nacional. Brasília: Diário Oficial da União, 27 dez. 1961. 
BRASIL. Lei no 9.424, de 24 de dezembro de 1996. Dispõe sobre o Fundo de Manutenção e Desenvolvimento do Ensino Fundamental e de Valorização do Magistério, na forma prevista no art. $60, \int 7^{\circ}$, do Ato das Disposições Constitucionais Transitórias, e dá outras providências. Brasília: Diário Oficial da União, 24 dez. 1996.

BRASIL. Ministério da Educação. Conselho Nacional de Educação. Parecer no 251/62. Brasília: MEC/CNE.

BRASIL. Ministério da Educação. Conselho Nacional de Educação. Parecer n. 252/69. Estudos pedagógicos superiores. Mínimos de currículo e duração para o curso de graduação em Pedagogia. Brasília: MEC/CNE.

COELHO, Ildeu Moreira. Curso de Pedagogia: a busca da identidade. Encontros e Debates Formação do educador: a busca da identidade do curso de Pedagogia. Brasília: MEC/INEP, 1987, p. 9-16.

FAUSTO, Boris. História do Brasil. São Paulo: EdUSP, 1996.

FERNANDEZ, Alice Beatriz Bitencourt. Histórico do curso de Pedagogia DED/CCHS/UFMS. In: V SEMINÁRIO DO CURSO DE PEDAGOGIA, 1989, Campo Grande. Anais do V SCP: Repensando o curso de Pedagogia. Campo Grande: Imprensa Universitária, 1989, p. 21-32.

FIORI, José Luis. O vôo da coruja: uma crítica não liberal à crise do Estado desenvolvimentista. Rio de Janeiro: EdUERJ, 1995.

FREITAS, Helena Costa Lopes. Formação de professores no Brasil: 10 anos de embate entre projetos de formação. Educação e Sociedade, Campinas, v. 23, n. 80, p. 136-167, set. 2002.

GATTI, Bernardete Angelina. Políticas docentes no Brasil: um estado da arte. Brasília: UNESCO, 2011.

GONÇALVES, Jane Mary Abuhassan. O curso de Pedagogia DED/CCHS na ótica de seus coordenadores. In: V SEMINÁRIO DO CURSO DE PEDAGOGIA, 1989, Campo Grande. Anais do V SCP: Repensando o curso de Pedagogia. Campo Grande: Imprensa Universitária, 1989, p. 33-38.

HARVEY, David. O neoliberalismo: história e implicações. São Paulo: Edições Loyola, 2008.

KULLOK, Maisa Gomes Brandão. As exigências da formação do professor na atualidade. Maceió: EdUFAL, 2000.

MACIEL, Lizete; NETO, Alexandre. (Orgs.). Formação de professores: passado, presente e futuro. São Paulo: Cortez, 2004.

MAYMONE, Hércules. Da farmácia e odontologia à Universidade: memórias. Campo Grande: Núcleo de Imprensa Universitária, Universidade Federal de Mato Grosso do Sul, 1989.

MENDONÇA, Ana Waleska. Anisio Teixeira e a universidade da educação. Rio de Janeiro: EdUERJ, 2002.

MENEZES, Ebenezer Takuno; SANTOS, Thais Helena. Verbete MEC/USAID. Dicionário Interativo da Educação Brasileira. São Paulo: Midiamix, 2001. 


\section{Edurañãa,Escola\&Sociedace}

MONTAÑO, Carlos. Terceiro Setor e questão social: crítica ao padrão emergente da intervenção social. 3. ed. São Paulo: Cortez, 2008.

MOON, Bob. O papel das novas tecnologias da comunicação e da educação à distância para responder à crise global na oferta e formação de professores: uma análise da experiência de pesquisa e desenvolvimento. Educação \& Sociedade, Campinas, v. 29, n. 104, p. 791-814, out. 2008.

ROMANELLI, Otaiza de Oliveira. História da Educação no Brasil. Petrópolis: Vozes, 1978.

SAVIANI, Dermeval. A nova lei da Educação: trajetória, limites e perspectivas. 3. ed. Campinas: Autores Associados, 1997.

SAVIANI, Dermeval. A Pedagogia no Brasil: história e teoria. Campinas: Autores Associados, 2008.

SAVIANI, Dermeval. Formação de professores: aspectos históricos e teóricos do problema no contexto brasileiro. Revista Brasileira de Educação, Rio de Janeiro, v. 14, n. 40, p. 143-155, jan./abr. 2009.

SCAFF, Elisângela Alves da Silva. Formação de professores da educação básica: avanços e desafios das políticas recentes. Linhas Críticas, Brasília, v. 17, n. 34, p. 461-481, set./dez. 2011.

SILVA, Carmem Silvia Bissolli. Curso de Pedagogia no Brasil: história e identidade. Campinas: Autores Associados, 1999.

SILVEIRA, Ramaís de Castro. Neoliberalismo: conceito e influências no Brasil — de Sarney a FHC. 2009. 176f. Dissertação (Mestrado em Ciência Política) - Instituto de Filosofia e Ciência Humana. Universidade Federal do Rio Grande do Sul. Porto Alegre.

SINDICATO DOS DOCENTES DA UNIVERSIDADE FEDERAL DE SANTA MARIA. Disponível em http://www.sedufsm.org.br/index.php?secao=greve; acesso em 20 fev. 2019.

UFMS. UNIVERSIDADE FEDERAL DE MATO GROSSO DO SUL. Portaria 129-A, de 15 de novembro de 1980. Regulamenta a estrutura curricular do curso de Pedagogia. Brasília: Diário Oficial da União, 15 nov. 1980.

UFMS. UNIVERSIDADE FEDERAL DE MATO GROSSO DO SUL. Portaria $\mathrm{n}^{\circ}$ 077/1981. Regulamenta as atividades da coordenação do curso. Brasília: Diário Oficial da União, 6 abr. 1981.

UFMS. UNIVERSIDADE FEDERAL DE MATO GROSSO DO SUL. Projeto Politico Pedagógico do Curso de Pedagogia da Universidade Federal de Mato Grosso do Sul. Campo Grande: UFMS, 2003.

UFMS. UNIVERSIDADE FEDERAL DE MATO GROSSO DO SUL. Relatório de autoavaliação setorial: centro de ciências humanas e sociais. Campo Grande: UFMS, 2013.

UFMS. UNIVERSIDADE FEDERAL DE MATO GROSSO DO SUL. Resolução n 121 , de 13 de dezembro de 1995. Aprova o currículo pleno do curso de Pedagogia habilitação magistério da pré-escola/CCHS. Brasília: Diário Oficial da União, 13 dez. 1995. 


\section{Edurañâ,Escolar Sociedace}

UFMS. UNIVERSIDADE FEDERAL DE MATO GROSSO DO SUL. Resolução n 121, de 13 de dezembro de 1995. Aprova o currículo pleno do curso de Pedagogia habilitação magistério da pré-escola/CCHS. Brasília: Diário Oficial da União, 15 nov. 1980.

UFMS. UNIVERSIDADE FEDERAL DE MATO GROSSO DO SUL. Resolução UFMS n $145 / 1990$. Aprova a estrutura curricular do curso. Brasília: Diário Oficial da União, 26 out. 1990.

VIEIRA, Evaldo. A República Brasileira 1951-2010: de Getúlio a Lula. São Paulo: Cortez, 2015. 